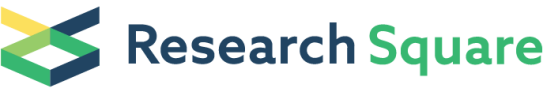 \\ Preprints are preliminary reports that have not undergone peer review. \\ They should not be considered conclusive, used to inform clinical practice, or referenced by the media as validated information.
}

\section{Assessment of Left Ventricular Dyssynchrony by Speckle Tracking Echocardiography in Children with Duchenne Muscular Dystrophy}

\section{Nicolas Lanot}

Centre Hospitalier Universitaire de Montpellier: Centre Hospitalier Regional Universitaire de Montpellier

\section{Marie Vincenti}

Centre Hospitalier Universitaire de Montpellier: Centre Hospitalier Regional Universitaire de Montpellier

\section{Hamouda Abassi}

Centre Hospitalier Universitaire de Montpellier: Centre Hospitalier Regional Universitaire de Montpellier

\section{Charlene Bredy}

Centre Hospitalier Universitaire de Montpellier: Centre Hospitalier Regional Universitaire de Montpellier

\section{Audrey Agullo}

Centre Hospitalier Universitaire de Montpellier: Centre Hospitalier Regional Universitaire de Montpellier

Lucie Gamon

Centre Hospitalier Universitaire de Montpellier: Centre Hospitalier Regional Universitaire de Montpellier

\section{Thibault Mura}

Centre Hospitalier Universitaire de Montpellier: Centre Hospitalier Regional Universitaire de Montpellier

\section{Kathleen Lavastre}

Centre Hospitalier Universitaire de Montpellier: Centre Hospitalier Regional Universitaire de Montpellier

\section{Gregoire De La Villeon}

Centre Hospitalier Universitaire de Montpellier: Centre Hospitalier Regional Universitaire de Montpellier

\section{Catherine Barrea}

Cliniques Universitaires Saint-Luc

\section{Pierre Meyer}

Centre Hospitalier Universitaire de Montpellier: Centre Hospitalier Regional Universitaire de Montpellier

\section{François Rivier}

Centre Hospitalier Universitaire de Montpellier: Centre Hospitalier Regional Universitaire de Montpellier

\section{Albano Melli}

Montpellier University: Universite de Montpellier

\section{Jeremy Fauconnier}

Université de Montpellier: Universite de Montpellier

\section{Olivier Cazorla}

Université de Montpellier: Universite de Montpellier

\section{Alain Lacampagne}

Université de Montpellier: Universite de Montpellier

\section{Pascal AMEDRO ( $\sim$ p-amedro@chu-montpellier.fr )}

Montpellier University Hospital https://orcid.org/0000-0003-3649-0294

\section{Research Article}


Keywords: cardiac dyssynchrony, speckle tracking, DMD, heart failure, pediatrics

Posted Date: May 13th, 2021

DOI: https://doi.org/10.21203/rs.3.rs-510752/v1

License: (c) (i) This work is licensed under a Creative Commons Attribution 4.0 International License. Read Full License

Version of Record: A version of this preprint was published at The International Journal of Cardiovascular Imaging on December 14th, 2021. See the published version at https://doi.org/10.1007/s10554-021-02369-y. 


\section{Abstract}

PurposePrognosis of Duchenne muscular dystrophy (DMD) is related to cardiac dysfunction. Two dimensional-speckle tracking echocardiography (2D-STE) has recently emerged as a non-invasive functional biomarker for early detection of DMD-related cardiomyopathy. This study aimed to determine, in DMD children, the existence of a left ventricle (LV) dyssynchrony using 2D-STE analysis.

Methods-This prospective controlled study enrolled 25 boys with DMD (mean age $11.0 \pm 3.5$ years) with normal LV ejection fraction and 50 age-matched controls. Three measures were performed to assess LV mechanical dyssynchrony: the opposing-wall delays (longitudinal and radial analyses), the modified Yu index, and the time-to-peak delays of each segment. Feasibility and reproducibility of 2D-STE dyssynchrony were evaluated.

Results-All three mechanical dyssynchrony criteria were significantly higher in the DMD group than in healthy subjects: (1) opposing-wall delays in basal inferoseptal to basal anterolateral segments $(61.4 \pm 45.3 \mathrm{msec}$ vs. $18.3 \pm 50.4 \mathrm{msec}$, $P<0.001$, respectively) and in mid inferoseptal to mid anterolateral segments ( $58.6 \pm 35.3 \mathrm{msec}$ vs. $42.4 \pm 36.4 \mathrm{msec}$, $P<0.05$, respectively), (2) modified Yu index (33.3 $\pm 10.1 \mathrm{msec}$ vs. $28.5 \pm 8.1 \mathrm{msec}, P<0.05$, respectively), and (3) most of time-to-peak values, especially in basal and mid anterolateral segments. Feasibility was excellent and reliability was moderate to excellent, with ICC values ranging from 0.49 to 0.97 .

Conclusion-Detection of LV mechanical dyssynchrony using 2D-STE analysis is an easily and reproducible method in pediatrics. The existence of an early LV mechanical dyssynchrony visualized using 2D-STE analysis in children with DMD before the onset of cardiomyopathy represents a perspective for future pediatric drug trials in the DMD-related cardiomyopathy prevention.

Clinical Trial Registration-Clinicaltrials.gov NCT02418338. Post-hoc study, registered on April 16, 2015.

\section{Introduction}

Duchenne muscular dystrophy (DMD) is an X-linked recessive myopathy leading to loss of dystrophin, a constitutive protein of muscle architecture. First symptoms usually appear by the age of 3 and result in loss of independent walking a few years later. Then, progressive symptoms occur, such as respiratory muscle weakness, skeletal deformations or gastro-intestinal disorders [1].

Heart failure due to progressive dilated cardiomyopathy usually occurs at the end of adolescence, and represents the main cause of death in this population [2]. Clinical presentation of DMD-related cardiomyopathy is often misleading, with poor symptomatology, less marked left ventricle (LV) dilatation, and worse prognosis than other etiologies of heart failure $[3,4]$.

Early identification of DMD-related cardiomyopathy is crucial in order to initiate heart failure medical treatments, improve quality of life, and try to slow down the progression of cardiomyopathy [5]. Cardiac screening is usually based on noninvasive echocardiography standard parameters, such as left ventricle ejection fraction (LVEF) and LV diameter, which are reliable and reproducible measures in pediatrics. However, alteration of those parameters appears at a late stage in DMDrelated cardiomyopathy natural history. Modern cardiac imaging tools, such as two-dimensional speckle tracking echocardiography (2D-STE), have shown some interest in terms of feasibility and early assessment of alteration in DMDrelated cardiomyopathy $[3,6,7]$. Indeed, from a prospective controlled study, we recently reported the existence of 2D-STE anomalies in children with DMD, before the onset of cardiomyopathy, especially in the longitudinal strain of basal inferolateral and anterolateral segments [6]. 
In the adult population with cardiomyopathy, such segmental myocardial alterations may be associated with cardiac dyssynchrony, regardless of the LVEF value [8-10]. Basically, cardiac dyssynchrony corresponds to nonsynchronous myocardial contractions, possibly related to three mechanisms: the electrical dyssynchrony, the mechanical dyssynchrony, and the excitation-contraction coupling anomalies [11, 12]. Ultimately, cardiac dyssynchrony may lead to hemodynamic failure [13-15].

To our knowledge, the existence of a cardiac dyssynchrony in children with DMD, before the onset of cardiomyopathy, has not been reported. Yet, in the modern era, pediatric DMD drug trials require reliable and non-invasive cardiac biomarkers. Identifying a pre-symptomatic cardiac biomarker would be of great interest in this population.

Therefore, this study aimed to identify cardiac dyssynchrony in children with DMD, before the onset of cardiomyopathy, in comparison with healthy age-matched control subjects.

\section{Methods}

\section{Study design and patients}

The patients included in this post-hoc study were screened from our recently published pediatric cohort [6]. We prospectively enrolled 0 to 18-year-old male with DMD and healthy age-matched controls recruited in three pediatric cardiology centers (Montpellier University Hospital, Montpellier, France; Saint-Pierre Institute, Palavas-Les-Flots, France; Cliniques Universitaires St-Luc, UCL University, Brussels, Belgium). Children with DMD were screened during their routine annual follow-up. For the present study, we included only patients with a normal left ventricular systolic function (LVEF $\geq$ $55 \%$ by the Simpson biplane method) from the previously reported cohort [6]. In the control group, we included agematched boys referred to the outpatient pediatric cardiology consultation for minor symptoms (e.g., innocent murmur, chest pain, palpitations, or sports certificate) and with normal physical examination, electrocardiogram, and conventional echocardiography. Children with any chronic disease, or under any treatment, were not included in the control group. Demographic and clinical data were collected in both groups. In the DMD group, cardiac treatment was noted and muscular stage was defined as follows: presymptomatic, early ambulatory, late ambulatory, early non-ambulatory, and late non-ambulatory [16].

\section{Conventional and 2D-strain echocardiography}

A single sonographer who traveled to the recruiting sites performed all echocardiographic examinations using the Vivid E9 ultrasound system (General Electric Healthcare, Little Chalfont, United Kingdom) and following the current echocardiographic guidelines [17]. Image acquisition procedures were harmonized using similar setting for each site: global gain, lateral gain, contrast, frame rates of 60 to 80 frames/sec to optimize myocardial deformation analysis, harmonic imaging, image colorizing, and probes adapted to the size and weight of the child (8 or $5 \mathrm{MHz}$ ). Three cardiaccycle loops were systematically recorded in the following views: apical four-, three-, and two-chamber views, and parasternal short-axis view focused on the papillary muscles. Whenever that was not possible, patient was excluded but reported as missing data in feasibility analysis.

Systolic and diastolic LV and right ventricle (RV) standard echocardiography parameters were measured.

Longitudinal LV 2D-strain analyses were performed off-line by a single investigator blinded of patient information, using the EchoPAC software (General Electric, version 203). Longitudinal LV 2D-strain analyses were carried out according to the consensus document of the EACVI/ASE/Industry Task Force [18]. The LV longitudinal and radial global and regional 2D-strain, and strain rate, were automatically calculated by the software after analysis of the 3 longitudinal and the parasternal short-axis views. 
Assessment of LV dyssynchrony

- Electrical LV dyssynchrony

From a 12-lead electrocardiogram (ECG), a single operator measured the duration of QRS intervals expressed in milliseconds ( $\mathrm{msec}$ ) on the V5 lead. For each subject, three measures were taken and averaged. To assess electrical dyssynchrony, QRS duration Z-scores were calculated using Chubb et al. formula [19], and we compared Z-scores values between DMD and control groups. Indeed, no evidence-based criteria have been described for electrical dyssynchrony in pediatrics. Based on epidemiological studies, cut-off values for prolonged QRS duration in pediatrics have been previously reported (90 msec in children < 4 years, and $100 \mathrm{msec}$ in 4-16 year-old children) [20]. More recently, Chubb et al. have determined pediatric Z-scores, and defined a cut-off value of 2.1 for prolonged QRS duration [19].

- Mechanical LV dyssynchrony

After performing 2D-strain analyses, the software generates deformation curves for each LV wall segment as a function of time, using a color code for each segment. Two sliders were manually positioned by a single investigator at the beginning of two consecutive QRS complexes, corresponding to the onset of ventricular depolarization, to mark the beginning and the end of the cardiac cycle on the curves graph. Then, the electrosystolic delay, e.g. the " time-to-peak » delay, was recorded. The time-to-peak delay was defined as the time between the beginning of the QRS complex and the systolic strain peak (Fig. 1). The systolic strain peak was defined as the maximum strain value during ventricular systole (occurring before aortic valve closure). The software provided an automatic calculation of time-to-peak delay for each segment, as represented in the shape of a 16-segment bull's eye model [18]. Due to known significant heart rate variability in children [21], all time-to-peak values were corrected using Bazett's formula, as recommended by Thomas et al [22].

To measure LV longitudinal mechanical dyssynchrony, three measures were performed: (1) the opposing-wall delay, corresponding to the delay between the systolic strain peak of two opposite walls, on basal and mid-levels[23, 24]; $(2)$ the modified Yu index, corresponding to the standard-deviation of time-to-peak values in the 12 basal and midwall segments [25], and measured using 2D-STE analysis in this study; and (3) the comparison of time-to-peak delays for each segment between DMD and control groups [26].

To assess LV radial dyssynchrony, we measured the anteroseptal-posterior opposing-wall delay, corresponding to the delay between the systolic strain peak of the mid posterior and the anteroseptal segments in parasternal short axis view [27-30]. This parameter was manually calculated by the same investigator: the systolic strain peak was identified on the curves graph, then the software automatically calculated the respective time-to-peak delay, and finally we deduced the anteroseptal-posterior opposing-wall delay.

\section{Feasibility and reproducibility analysis}

Patients with a poor acoustic window or a poor-quality ECG pattern (illegible or containing less than one complete cardiac cycle) were excluded from dyssynchrony analysis and collected as feasibility data.

To assess interobserver and intraobserver reproducibility, a second analysis of time-to-peak delays in the 16 LV segments was performed by the same investigator and by a second investigator (AA), with no access to the results of first analysis, on a subset of 20 patients randomly selected from the two groups.

\section{Statistical analysis}

Each child with DMD was matched with 2 control subjects according to four age groups (0-4 years, 5-8 years, 9-12 years, and 13-17 years). The characteristics of the children enrolled in the study were described with proportions for categorical variables and with means and standard deviation values for continuous variables. The comparisons of 
echocardiographic parameters (conventional, 2D-strain and dyssynchrony analyses) between children with DMD and control subjects were performed using linear mixed models. These models included a random intercept specific to matched triads. DMD and age were entered as fixed effects in models.

In accordance with recommendations published in Shrout and Fleiss [31], we evaluated the reproducibility of the performed measurements by calculating intraclass correlation coefficients (ICC) of type $(2,1)$ for interobserver and intraobserver reliability, as only one investigator was responsible for the double analysis to assess intraobserver reliability, and a single pair of investigators produced the two analyses to assess interobserver reliability. As defined by Koo et al., ICC values less than 0.5 , between 0.5 and 0.75 , between 0.75 and 0.9 , and greater than 0.90 were indicative of poor, moderate, good, and excellent reliability, respectively [32]. Analyses were performed using SAS version 9 (SAS Institute, Cary, NC, USA). The statistical significance was set at 0.05 .

\section{Results}

\section{Population}

A total of 75 children were enrolled in the study, including 25 patients with DMD (mean age, $11.0 \pm 3.5$ years) and 50 agematched healthy male controls (mean age, $10.0 \pm 3.3$ years). The heart rate was significantly higher in the DMD group than in healthy subjects ( $95 \pm 13 \mathrm{bpm}$ vs. $74 \pm 12 \mathrm{bpm}, P<0.01$, respectively). Cardiovascular symptoms were reported in only one child with DMD (exercise-induced dyspnea). The main muscular stage was "early non-ambulatory". Combination therapy with corticosteroids and angiotensin converting enzyme (ACE) inhibitors was the most common drug treatment. Demographic and clinical data are summarized in Table 1. 
Population characteristics

\begin{tabular}{|c|c|c|c|c|}
\hline \multicolumn{2}{|l|}{ Clinical parameters } & $\begin{array}{l}\text { DMD group }(\mathrm{N}= \\
25)\end{array}$ & $\begin{array}{l}\text { Control group }(\mathrm{N}= \\
50)\end{array}$ & $\begin{array}{l}\mathrm{P} \text { - } \\
\text { value }\end{array}$ \\
\hline \multicolumn{2}{|l|}{ Age (year) } & $11.0 \pm 3.5$ & $10.0 \pm 3.25$ & NA \\
\hline \multicolumn{2}{|l|}{ Weight (kg) } & $37.7 \pm 15.3$ & $37.5 \pm 15.5$ & 0.14 \\
\hline \multicolumn{2}{|l|}{ Height (cm) } & $136.5 \pm 16.0$ & $143.1 \pm 19.6$ & $<.001$ \\
\hline \multicolumn{2}{|l|}{ BMI $\left(\mathrm{kg} / \mathrm{m}^{2}\right)$} & $19.1 \pm 5.6$ & $17.5 \pm 3.0$ & 0.14 \\
\hline \multicolumn{2}{|l|}{$\begin{array}{l}\text { Systolic blood pressure } \\
(\mathrm{mmHg})\end{array}$} & $107.8 \pm 10.1$ & $107.1 \pm 13.2$ & 0.75 \\
\hline \multicolumn{2}{|l|}{$\begin{array}{l}\text { Diastolic blood pressure } \\
(\mathrm{mmHg})\end{array}$} & $61.6 \pm 7.9$ & $56.1 \pm 8.0$ & 0.01 \\
\hline \multicolumn{2}{|l|}{ Heart rate (bpm) } & $95.4 \pm 12.9$ & $73.8 \pm 11.7$ & $<.001$ \\
\hline \multirow[t]{5}{*}{ Muscular stage } & Pre-symptomatic & $3(12 \%)$ & - & - \\
\hline & Early ambulatory & $5(20 \%)$ & - & - \\
\hline & Late ambulatory & $3(12 \%)$ & - & - \\
\hline & Early non-ambulatory & $13(52 \%)$ & - & - \\
\hline & Late non-ambulatory & $1(4 \%)$ & - & - \\
\hline \multirow[t]{5}{*}{ Cardiac treatment } & None & $2(8 \%)$ & - & - \\
\hline & Corticosteroids & $2(8 \%)$ & - & - \\
\hline & ACE inhibitors & $5(20 \%)$ & - & - \\
\hline & $\begin{array}{l}\text { Corticosteroids + ACE } \\
\text { inhibitors }\end{array}$ & $14(56 \%)$ & - & - \\
\hline & Others & $2(8 \%)$ & - & - \\
\hline \multicolumn{2}{|l|}{ Cardiovascular symptoms } & $1(4 \%)$ & - & - \\
\hline
\end{tabular}

\section{Conventional and 2D-strain echocardiography variables}

Mean LVEF was normal and similar between groups $(63 \% \pm 5 \%$ in the DMD group vs. $64 \% \pm 5 \%$ in the control group, $P=$ 0.8). No significant LV dilatation was observed in the DMD group. RV conventional variables were normal and similar between the two groups. Conventional echocardiography variables are reported in Table 2. 
Table 2

Conventional echocardiography variables

\begin{tabular}{|c|c|c|c|c|c|c|}
\hline \multicolumn{2}{|c|}{$\begin{array}{l}\text { Conventional echocardiography } \\
\text { variables }\end{array}$} & \multirow{2}{*}{$\begin{array}{l}\text { DMD group }(\mathrm{N}= \\
\text { 25) } \\
\text { Mean } \pm \text { SD }\end{array}$} & \multirow{2}{*}{$\begin{array}{l}\text { Controls }(\mathrm{N}= \\
50) \\
\text { Mean } \pm \text { SD }\end{array}$} & \multicolumn{3}{|c|}{$\begin{array}{l}\text { Adjusted difference between } \\
\text { groups* }\end{array}$} \\
\hline & & & & Coefficient & [95\% Cl] & $\begin{array}{l}\mathrm{P}- \\
\text { value }\end{array}$ \\
\hline \multirow{7}{*}{$\begin{array}{l}\text { Left } \\
\text { ventricle }\end{array}$} & LVEF (\%) & $63.5 \pm 5.1$ & $63.8 \pm 5.0$ & -0.25 & {$[-2.5 ; 2.0]$} & 0.8 \\
\hline & LVIDd (mm) & $39.3 \pm 4.2$ & $42.3 \pm 4.2$ & -3.83 & $\begin{array}{l}{[-5.5} \\
-2.1]\end{array}$ & $\dot{0} 001$ \\
\hline & E/A ratio & $1.8 \pm 0.4$ & $2.2 \pm 0.6$ & -0.39 & $\begin{array}{l}{[-0.7 ;} \\
-0.1]\end{array}$ & 0.01 \\
\hline & $\begin{array}{l}\text { E deceleration time } \\
\text { (msec) }\end{array}$ & $144.4 \pm 25.7$ & $175.8 \pm 37.0$ & -35.02 & $\begin{array}{l}{[-52.5} \\
-17.6]\end{array}$ & $\dot{0} 001$ \\
\hline & $E / E^{\prime}$ & $5.8 \pm 1.9$ & $5.7 \pm 1.1$ & 0.15 & {$[-0.5 ; 0.8]$} & 0.7 \\
\hline & Wall stress $\left(\mathrm{g} / \mathrm{cm}^{2}\right)$ & $49.9 \pm 14.9$ & $42.7 \pm 10.8$ & 7.69 & $\begin{array}{l}{[1.2} \\
14.2]\end{array}$ & 0.02 \\
\hline & $\operatorname{VCFc}\left(s^{-1}\right)$ & $1.4 \pm 0.4$ & $1.3 \pm 0.2$ & 0.15 & {$[0.0 ; 0.3]$} & 0.03 \\
\hline \multirow{4}{*}{$\begin{array}{l}\text { Right } \\
\text { ventricle }\end{array}$} & TAPSE (mm) & $19.5 \pm 2.5$ & $20.8 \pm 3.4$ & -1.42 & {$[-2.9 ; 0.1]$} & 0.06 \\
\hline & S wave (TDI) $(\mathrm{cm} / \mathrm{s})$ & $13.0 \pm 2.4$ & $12.9 \pm 1.9$ & 0.08 & {$[-0.9 ; 1.1]$} & 0.9 \\
\hline & TEl index (TDI) & $0.4 \pm 0.1$ & $0.4 \pm 0.1$ & -0.02 & {$[-0.1 ; 0.1]$} & 0.6 \\
\hline & IVC \% & $62.3 \pm 19.4$ & $69.3 \pm 17.1$ & -7.05 & $\begin{array}{l}{[-16.9} \\
2.8]\end{array}$ & 0.2 \\
\hline \multicolumn{7}{|c|}{$\begin{array}{l}\text { Legend: LVEF, left ventricle ejection fraction (Simpson biplane); LVIDd, left ventricle internal diastolic diameter; TDI, } \\
\text { tissue Doppler imaging; VCFC, contraction velocity corrected by cardiac frequency; TAPSE, tricuspid annular plane } \\
\text { systolic excursion; TEl, myocardial performance index; IVC \%, inferior vena cava collapse index. }\end{array}$} \\
\hline
\end{tabular}

Global LV 2D-strain values were significantly lower in the DMD group than in the control group, for both longitudinal analysis $(-16.8 \% \pm 3.9 \%$ vs. $-20.6 \% \pm 2.6 \%, P<0.0001$, respectively) and radial analysis $(22.7 \% \pm 11.3 \%$ vs. $31.7 \% \pm 14.0 \%$, $\mathrm{P}<0.002$, respectively). Regional 2D-strain values were significantly lower in the DMD group for LV inferolateral, anterolateral, anterior and inferior regions, with a greatest difference for the inferior and anterolateral segments. No differences were observed in terms of strain rate (for both longitudinal and radial analyses) and regional 2D-strain for LV basal anteroseptal, inferoseptal and apical anterior segments. Global and regional LV 2D-strain and strain rate analyses are reported in supplementary Table S1 (longitudinal strain) and supplementary Table S2 (radial strain).

\section{Left ventricular dyssynchrony analysis}

- Electrical LV dyssynchrony

No QRS widening was observed in the DMD group. Mean QRS complex measures were not significantly different between DMD and control groups ( $83 \pm 10 \mathrm{msec}$ vs. $85 \pm 11 \mathrm{msec}, P=0.07$, respectively). Z-scores of QRS width were normal and similar between the two groups ( $-0.2 \pm 0.8$ vs. $0.2 \pm 0.9, P=0.08$, respectively).

- Mechanical LV dyssynchrony 
The basal inferoseptal to basal anterolateral opposing-wall delay was significantly higher in the DMD group than in healthy subjects $(61.4 \pm 45.3 \mathrm{msec}$ vs. $18.3 \pm 50.4 \mathrm{msec}, P<0.001$, respectively). Similarly, the mid inferoseptal to mid anterolateral opposing-wall delay was significantly higher in the DMD group than in healthy controls ( $58.6 \pm 35.3 \mathrm{msec}$ vs. $42.4 \pm 36.4 \mathrm{msec}, P<0.05$, respectively). There was a trend for a higher difference between the basal anteroseptal and basal inferolateral segments in the DMD group than in healthy controls $(-47.6 \pm-63.8 \mathrm{msec}$ vs. $-30.2 \pm-41.1 \mathrm{msec}, P=$ 0.11 , respectively). No other difference was observed in the longitudinal analysis, as well as in the radial analysis.

The modified Yu index was significantly higher in the DMD group than in healthy subjects $(33.3 \pm 10.1 \mathrm{msec} v \mathrm{vs} .28 .5 \pm 8.1$ msec, $P<0.05$, respectively).

Time-to-peak delays in the DMD group were significantly increased in basal and mid anterior and anterolateral segments, as well as in the apical lateral segment (Fig. 2, Table 3). 
Table 3

Opposing-wall delays in longitudinal and radial 2D-strain analyses

\begin{tabular}{|c|c|c|c|c|c|c|c|c|c|}
\hline & & & \multicolumn{2}{|c|}{ DMD group } & \multicolumn{2}{|c|}{ Controls } & \multicolumn{3}{|c|}{$\begin{array}{l}\text { Adjusted difference between } \\
\text { groups* }\end{array}$} \\
\hline & & & $\mathrm{N}$ & $\begin{array}{l}\text { Mean } \\
\pm S D\end{array}$ & $\mathrm{~N}$ & $\begin{array}{l}\text { Mean } \\
\pm S D\end{array}$ & Coefficient & $\begin{array}{l}{[95 \%} \\
\mathrm{Cl}]\end{array}$ & $\begin{array}{l}\mathrm{P}- \\
\text { value }\end{array}$ \\
\hline \multirow{6}{*}{$\begin{array}{l}\text { LV } \\
\text { longitudinal } \\
\text { opposing- } \\
\text { wall delay }\end{array}$} & $\begin{array}{l}\text { Basal } \\
\text { segments }\end{array}$ & $\begin{array}{l}\text { 4- } \\
\text { chamber } \\
\text { view }\end{array}$ & 25 & $\begin{array}{l}61.4 \\
\pm 45.3\end{array}$ & 50 & $\begin{array}{l}18.3 \\
\pm 50.4\end{array}$ & 46.8 & $\begin{array}{l}{[23.1} \\
70.5]\end{array}$ & $\hat{0} .001$ \\
\hline & & $\begin{array}{l}\text { 3- } \\
\text { chamber } \\
\text { view }\end{array}$ & 25 & $\begin{array}{l}-47.6 \\
\pm 63.8\end{array}$ & 50 & $\begin{array}{l}-30.2 \\
\pm 41.1\end{array}$ & -19.7 & $\begin{array}{l}{[-44.3} \\
4.8]\end{array}$ & 0.11 \\
\hline & & $\begin{array}{l}\text { 2- } \\
\text { chamber } \\
\text { view }\end{array}$ & 25 & $\begin{array}{l}9.9 \pm \\
50.6\end{array}$ & 50 & $\begin{array}{l}5.2 \pm \\
45.4\end{array}$ & 0.2 & $\begin{array}{l}{[-0.5 ;} \\
0.9]\end{array}$ & 0.64 \\
\hline & $\begin{array}{l}\text { Mid } \\
\text { segments }\end{array}$ & $\begin{array}{l}\text { 4- } \\
\text { chamber } \\
\text { view }\end{array}$ & 25 & $\begin{array}{l}58.6 \\
\pm 35.3\end{array}$ & 50 & $\begin{array}{l}42.4 \\
\pm 36.4\end{array}$ & 18.0 & $\begin{array}{l}{[0.2 ;} \\
35.8]\end{array}$ & $\hat{0} .05$ \\
\hline & & $\begin{array}{l}\text { 3- } \\
\text { chamber } \\
\text { view }\end{array}$ & 25 & $\begin{array}{l}-20.4 \\
\pm 51.7\end{array}$ & 50 & $\begin{array}{l}-12.6 \\
\pm 40.1\end{array}$ & -9.5 & $\begin{array}{l}{[-31.1} \\
12.1]\end{array}$ & 0.38 \\
\hline & & $\begin{array}{l}\text { 2- } \\
\text { chamber } \\
\text { view }\end{array}$ & 25 & $\begin{array}{l}18.1 \\
\pm 45.6\end{array}$ & 50 & $\begin{array}{l}14.3 \\
\pm 38.3\end{array}$ & 2.4 & $\begin{array}{l}{[-17.9} \\
22.8]\end{array}$ & 0.81 \\
\hline $\begin{array}{l}\text { LV radial } \\
\text { mechanical } \\
\text { opposing- } \\
\text { wall delay }\end{array}$ & & & 23 & $\begin{array}{l}-17.3 \\
\pm 29.3\end{array}$ & 49 & $\begin{array}{l}-24.2 \\
\pm 33.5\end{array}$ & 8.2 & $\begin{array}{l}{[-8.6 ;} \\
25.1]\end{array}$ & 0.33 \\
\hline \multicolumn{10}{|c|}{ Legend: LV, left ventricle. } \\
\hline \multicolumn{10}{|c|}{$\begin{array}{l}\text { *Difference between groups adjusted for age; corrected by heart rate (using Bazett's formula); significant } p \text {-values are } \\
\text { marked in bold. }\end{array}$} \\
\hline \multicolumn{10}{|c|}{$\begin{array}{l}\text { 1LV mechanical dyssynchrony was assessed as the difference between the time-to-peak value of the basal } \\
\text { inferoseptal and the basal anterolateral segments (4-chambers view), between the basal inferolateral and the basal } \\
\text { anteroseptal segments (3-chamber view), and between the basal inferior and the basal anterior segments (2-chamber } \\
\text { view). }\end{array}$} \\
\hline \multicolumn{10}{|c|}{$\begin{array}{l}\text { 2LV mechanical dyssynchrony was assessed as the difference between the time-to-peak value of the mid inferoseptal } \\
\text { and the mid anterolateral segments (4-chamber view), between the mid inferolateral and the mid anteroseptal } \\
\text { segments (3-chamber view), and between the mid inferior and the basal anterior segments (2-chamber view). }\end{array}$} \\
\hline
\end{tabular}

\section{Feasibility and reproducibility analysis}

From our previously reported database [6], 30 children with DMD and 72 healthy control subjects were eligible for the study. The proportion of patients excluded from dyssynchrony analysis was similar in the two groups (5 out of 30 patients, i.e. $16.7 \%$ in the DMD group, and 13 out of 72 patients, i.e. $18.0 \%$ in the control group). In the DMD group, one subject (3.3\%) was excluded due to poor acoustic window, making LV dyssynchrony analysis impossible, and four subjects (13.3\%) had a poor-quality ECG pattern. In two patients (6.7\%), 2D-strain analysis was only possible in apical views. 
In the control group, one subject (1.4\%) was excluded from analysis due to poor acoustic window, making LV dyssynchrony analysis impossible, and 12 subjects (16.7\%) had a poor-quality ECG pattern. In one patient (3.4\%), 2Dstrain analysis was only possible in apical views. Therefore, LV dyssynchrony analysis was feasible in a total of 59 healthy subjects. As 25 children with DMD were enrolled in the study, 50 age-matched healthy subjects were selected in order to respect the 1:2 case-control study design.

Intra-observer and inter-observer reliability analyses of time-to-peak delays in the 16 LV segments were reported in Table 4. We found moderate to excellent levels of reliability with ICC values ranging from 0.60 to 0.97 for intraobserver variability and from 0.49 to 0.94 for interobserver variability.

Table 4

Intra- and interobserver variability of time-to-peak delays

\begin{tabular}{|c|c|c|c|c|}
\hline \multirow[t]{2}{*}{ LV segments } & \multicolumn{2}{|c|}{$\begin{array}{l}\text { Intraobserver variability } \\
(\mathrm{N}=20)\end{array}$} & \multicolumn{2}{|c|}{$\begin{array}{l}\text { Interobserver variability } \\
(\mathrm{N}=20)\end{array}$} \\
\hline & ICC & [95\% Cl] & ICC & [95\% Cl] \\
\hline Basal anterior & 0.78 & {$[0.53 ; 0.91]$} & 0.81 & {$[0.58 ; 0.92]$} \\
\hline Basal anteroseptal & 0.82 & {$[0.62 ; 0.93]$} & 0.85 & {$[0.99 ; 0.94]$} \\
\hline Basal inferoseptal & 0.89 & {$[0.74 ; 0.95]$} & 0.77 & {$[0.51 ; 0.90]$} \\
\hline Basal inferior & 0.60 & {$[0.24 ; 0.82]$} & 0.49 & {$[0.08 ; 0.76]$} \\
\hline Basal inferolateral & 0.89 & {$[0.75 ; 0.96]$} & 0.74 & {$[0.44 ; 0.89]$} \\
\hline Basal anterolateral & 0.91 & {$[0.79 ; 0.96]$} & 0.73 & {$[0.44 ; 0.88]$} \\
\hline Mid anterior & 0.62 & {$[0.27 ; 0.83]$} & 0.72 & {$[0.42 ; 0.88]$} \\
\hline Mid anteroseptal & 0.74 & {$[0.45 ; 0.88]$} & 0.72 & {$[0.42 ; 0.88]$} \\
\hline Mid inferoseptal & 0.91 & {$[0.79 ; 0.96]$} & 0.84 & {$[0.65 ; 0.93]$} \\
\hline Mid inferior & 0.87 & {$[0.71 ; 0.95]$} & 0.71 & {$[0.41 ; 0.87]$} \\
\hline Mid inferolateral & 0.91 & {$[0.78 ; 0.94]$} & 0.66 & {$[0.32 ; 0.85]$} \\
\hline Mid anterolateral & 0.96 & {$[0.88 ; 0.98]$} & 0.92 & {$[0.81 ; 0.96]$} \\
\hline Apical anterior & 0.85 & {$[0.67 ; 0.94]$} & 0.94 & {$[0.86 ; 0.98]$} \\
\hline Apical septal & 0.97 & {$[0.94 ; 0.99]$} & 0.94 & {$[0.85 ; 0.98]$} \\
\hline Apical inferior & 0.96 & {$[0.90 ; 0.98]$} & 0.79 & {$[0.52 ; 0.91]$} \\
\hline Apical lateral & 0.94 & {$[0.86 ; 0.98]$} & 0.87 & {$[0.69 ; 0.94]$} \\
\hline
\end{tabular}

\section{Discussion}

This prospective controlled study reported, for the first time, the existence of a left ventricular regionalized mechanical dyssynchrony in children with DMD with a normal LV systolic function. Indeed, using 2D-STE analysis, all three mechanical dyssynchrony criteria evaluated in this study were significantly higher in the DMD group than in healthy matched subjects: (1) basal inferoseptal to basal anterolateral opposing-wall delay and mid inferoseptal to mid 
anterolateral opposing-wall delay, (2) modified Yu index, and (3) most of time-to-peak delays, especially in basal and mid anterolateral segments.

Interestingly, this study found a segmental LV mechanical dyssynchrony before the onset of DMD-related cardiomyopathy or any clinical symptoms, as no patient with LV systolic dysfunction or LV dilatation was enrolled. LV mechanical dyssynchrony was more pronounced in the basal and mid anterolateral segments, which is concordant with LV 2D-strain anomalies previously observed in similar segments [6, 7].

Indeed, selective damage in those segments may be related to regional myocardial scar, which has been found to be higher in lateral than in septal segments, even with a preserved LV systolic function. Hor et al. have previously reported that LV mechanical dyssynchrony in DMD with end-stage cardiac dysfunction was associated with extensive infero- and anterolateral fibrosis [33]. Using cardiac magnetic resonance imaging, Bilchick et al. have also shown that myocardial scar affected the LV anterolateral segment eight times more than the septal wall, regardless of LV systolic function [34]. Furthermore, analyses on anatomopathology, electrocardiograms, and vectorcardiograms in DMD patients have suggested that fibrosis would start from the epimyocardial portion of the LV lateral wall, then reach the septal wall, and finally extent to the entire thickness of the myocardial wall [35]. DMD-related fibrosis has been associated with myocardial stiffness, reduced myocyte compliance and increased susceptibility to stretch-mediated calcium overload, inducing cell necrosis [36]. Moreover, LV mechanical dyssynchrony could modify myocardial gene expression and aggravate heart failure, as described in mouse models of cardiac remodeling [37]. However, the reason why fibrosis first involves this specific ventricular region remains unknown.

In this pediatric cohort, 2D-STE dyssynchrony analyses have shown good feasibility and reproducibility, as previously reported in children without any cardiac disease [38]. Indeed, in our study, analyses were technically possible in more than $80 \%$ of children in both DMD and healthy subjects, which is the line with the STAR study in adult heart failure [23]. Overall, reproducibility was good to excellent, especially in segments where mechanical LV dyssynchrony was observed.

Other ultrasound methods have been used to measure mechanical LV dyssynchrony [39]. However, M-mode and tissue Doppler imaging (TDI) do not provide simultaneous sampling in multiple segments. Color-coded tissue Doppler, tissue synchronization imaging and 3D-echocardiography provide simultaneous sampling of multiple segments, but require high-end ultrasound equipment and are difficult to use in current practice [40]. 2D-STE analysis is little affected by translational and tethering motions [41, 42], and is not angle dependent. Moreover, 2D-STE semi-automated processing improves reproducibility and provides a global assessment of LV wall deformations, with easier use than other methods [40].

In this study, no electrical dyssynchrony was observed in children with DMD. Indeed, QRS intervals were similar between DMD and healthy subjects, using both raw values and pediatric Z-scores. This result is in line with the study from Hor et al., using cardiac magnetic resonance imaging in children with DMD and finding that the existence of a LV mechanical dyssynchrony did not involve electrical dyssynchrony in the DMD population [33]. Therefore, measuring QRS intervals remains insufficient for assessing cardiac damage in patients with DMD.

Currently, cardiomyopathy prevention represents one of the most challenging clinical research issues in children with DMD [43]. Conventional echocardiography parameters have failed to determine drugs' efficacy (angiotensin-converting enzyme inhibitors, $\beta$-blockers, corticosteroids) on DMD cardiomyopathy onset and progression rate [5, 44-47]. Moreover, available tools to evaluate cardiac function may not be very specific (biological blood tests), difficult to perform in pediatric patients (cardiac magnetic resonance imaging), or too invasive (myocardial biopsy). Therefore, using mechanical dyssynchrony as a novel non-invasive cardiac biomarker in current (phosphodiesterase-5 inhibitors, COXinhibiting nitric oxide donators, poloxamer 188) or future pediatric DMD drug trials would be of great interest.

Page $12 / 20$ 
The results of this study evidently question the interest of cardiac resynchronization therapy (CRT) in the DMD population. In adult symptomatic heart failure with impaired systolic LV function and LV mechanical dyssynchrony, CRT may improve symptoms and LV reverse remodeling, regardless of QRS width $[48,49]$. However, in adult ischemic heart disease, the existence of inferior fibrosis reaching more than $50 \%$ wall thickness is associated with a nonresponse to CRT [50]. LV pacing may reduce the progression of DMD-related cardiomyopathy, by decreasing ventricular work at each heartbeat, and therefore reducing damage to the myocyte membrane [34,36]. By analogy, we may hypothesize that CRT could prevent LV mechanical dyssynchrony at an early stage of the cardiomyopathy, inducing a clinical benefit for the patient. Nevertheless, more evidence is necessary to support that CRT is useful in the DMD population free from heart failure.

\section{Study limitations}

The original study was not designed to use mechanical dyssynchrony as a primary outcome [6]. As a result, the population from this post-hoc study included a small number of patients and controls. No subgroup analyses could be performed, however all three mechanical dyssynchrony criteria reached statistical significance.

No cut-off values to define LV electrical or mechanical dyssynchrony have been established in the pediatric population. As a result, we used a case-control study design to compare DMD patients to age-matched healthy subjects. Further studies are needed to define LV dyssynchrony thresholds in pediatrics.

The cross-sectional design of this study limits the use of LV mechanical dyssynchrony as a prognostic marker of LV dysfunction. Indeed, further longitudinal cohort studies will need to determine whether LV mechanical dyssynchrony can be used as a surrogate outcome for heart failure in the DMD population.

\section{Conclusion}

LV mechanical dyssynchrony involving the basal and mid anterolateral segments seemed to affect children with DMD before the onset of relevant patterns of cardiomyopathy. Detection of LV mechanical dyssynchrony using the 2D-STE analysis is an easily and reproducible method, which may be of interest in clinical practice.

The existence of 2D-STE mechanical dyssynchrony despite normal LV size and function represents an important perspective for future pediatric drug trials in DMD-related cardiomyopathy prevention. Further prospective studies will be necessary to confirm that cardiac dyssynchrony parameters may be used as reliable surrogate outcomes for heart failure in patients with DMD.

\section{Abbreviations}

2D-strain

two-dimensional strain

2D-STE

two-dimensional speckle tracking echocardiography

ACE

angiotensin converting enzyme.

CRT

cardiac resynchronization therapy

DMD

Duchenne muscular dystrophy

ECG 
electrocardiogram

ICC

intraclass correlation coefficient

LV

left ventricle

LVEF

left ventricle ejection fraction (biplane Simpson)

LVIDd

left ventricle internal diastolic diameter

RV

right ventricle

TDI

tissue Doppler imaging

VCFC

contraction velocity corrected by cardiac frequency

\section{Declarations}

\section{Funding}

This work was supported by grants from Montpellier University Hospital Clinical Research Institutional Grant [PHRCMERRI UF 9458] and from the French National Muscular Dystrophy Association [AFM 20225].

\section{Conflicts of Interest}

The authors declare that they have no conflict of interest.

\section{Availability of data and material}

The data that support the findings of this study are available from the corresponding author, upon reasonable request.

\section{Code availability}

Not applicable.

\section{Author's contributions}

Pascal Amedro and Alain Lacampagne conceived and designed the study. Pascal Amedro, Jeremy Fauconnier, Olivier Cazorla and Alain Lacampagne obtained funding. Pascal Amedro supervised this work. Nicolas Lanot and Marie Vincenti performed image acquisition and analysis. Lucie Gamon and Thibault Mura performed the statistical analysis. Pascal Amedro, Nicolas Lanot, Marie Vincenti, Hamouda Abassi, Gregoire De La Villeon, Kathleen Lavastre, Albano C. Meli, Olivier Cazorla, Jeremy Fauconnier, and Alain Lacampagne drafted the manuscript. All authors discussed the results and contributed to the final revision of the manuscript.

\section{Ethics approval}

The study was conducted in compliance with the Good Clinical Practices protocol and Declaration of Helsinki principles. The South Mediterranean IV Ethics Committee (2014-A01764-44) in France and the UCL Ethics Committee (2016-28AVR192) in Belgium approved the study. 


\section{Consent to participate}

Informed consent was obtained from all parents or legal guardians.

\section{Consent for publication}

Informed consent was obtained from all parents or legal guardians. Only anonymized data has been published.

\section{Acknowledgments}

We thank all our patients and their families for their participation in the study, and Anne Cadene for the quality of study monitoring.

\section{Sources of funding}

This work was supported by grants from Montpellier University Hospital Clinical Research Institutional Grant [PHRCMERRI UF 9458] and from the French National Muscular Dystrophy Association [AFM 20225].

\section{Ethical standards}

The study was conducted in compliance with the Good Clinical Practices protocol and Declaration of Helsinki principles. The South Mediterranean IV Ethics Committee (2014-A01764-44) in France and the UCL Ethics Committee (2016-28AVR192) in Belgium approved the study, which was registered on ClinicalTrials.gov (NCT02418338). Informed consent was obtained from all parents or legal guardians.

\section{References}

1. Guiraud S, Aartsma-Rus A, Vieira NM, Davies KE, van Ommen G-JB, Kunkel LM. The Pathogenesis and Therapy of Muscular Dystrophies. Annu Rev Genomics Hum Genet. 2015;16:281-308. https://doi.org/10.1146/annurev-genom090314-025003

2. Kamdar F, Garry DJ. Dystrophin-Deficient Cardiomyopathy. J Am Coll Cardiol. 2016;67:2533-46. https://doi.org/10.1016/j.jacc.2016.02.081

3. Spurney CF, McCaffrey FM, Cnaan A, Morgenroth LP, Ghelani SJ, Gordish-Dressman H, et al. Feasibility and Reproducibility of Echocardiographic Measures in Children with Muscular Dystrophies. J Am Soc Echocardiogr Off Publ Am Soc Echocardiogr. 2015;28:999-1008. https://doi.org/10.1016/j.echo.2015.03.003

4. Connuck DM, Sleeper LA, Colan SD, Cox GF, Towbin JA, Lowe AM, et al. Characteristics and outcomes of cardiomyopathy in children with Duchenne or Becker muscular dystrophy: a comparative study from the Pediatric Cardiomyopathy Registry. Am Heart J. 2008;155:998-1005. https://doi.org/10.1016/j.ahj.2008.01.018

5. Duboc D, Meune C, Lerebours G, Devaux J-Y, Vaksmann G, Bécane H-M. Effect of perindopril on the onset and progression of left ventricular dysfunction in Duchenne muscular dystrophy. J Am Coll Cardiol. 2005;45:855-7. https://doi.org/10.1016/j.echo.2018.10.017

6. Amedro P, Vincenti M, De La Villeon G, Lavastre K, Barrea C, Guillaumont S, et al. Speckle-Tracking Echocardiography in Children With Duchenne Muscular Dystrophy: A Prospective Multicenter Controlled Cross-Sectional Study. J Am Soc Echocardiogr Off Publ Am Soc Echocardiogr. 2019;32:412-22. https://doi.org/10.1016/j.echo.2018.10.017

7. Mertens L, Ganame J, Claus P, Goemans N, Thijs D, Eyskens B, et al. Early regional myocardial dysfunction in young patients with Duchenne muscular dystrophy. J Am Soc Echocardiogr Off Publ Am Soc Echocardiogr. 2008;21:104954. https://doi.org/10.3233/jnd-160194 
8. Chang S-A, Kim H-K, Kim D-H, Kim Y-J, Sohn D-W, Oh B-H, et al. Left ventricular systolic and diastolic dyssynchrony in asymptomatic hypertensive patients. J Am Soc Echocardiogr Off Publ Am Soc Echocardiogr. 2009;22:337-42. https://doi.org/10.1016/j.echo.2009.01.024

9. Wang J, Kurrelmeyer KM, Torre-Amione G, Nagueh SF. Systolic and diastolic dyssynchrony in patients with diastolic heart failure and the effect of medical therapy. J Am Coll Cardiol. 2007;49:88-96. https://doi.org/10.1016/j.jacc.2006.10.023

10. Edvardsen T, Helle-Valle T, Smiseth OA. Systolic Dysfunction in Heart Failure with Normal Ejection Fraction: SpeckleTracking Echocardiography. Prog Cardiovasc Dis. 2006;49:207-14. https://doi.org/10.1016/j.pcad.2006.08.008

11. Yu CM, Bax JJ, Monaghan M, Nihoyannopoulos P. Echocardiographic evaluation of cardiac dyssynchrony for predicting a favourable response to cardiac resynchronisation therapy. Heart. BMJ Publishing Group Ltd; 2004;90:vi17-22. https://doi.org/10.1136/hrt.2004.048322

12. Vardas PE, Auricchio A, Blanc J-J, Daubert J-C, Drexler H, Ector H, et al. Guidelines for cardiac pacing and cardiac resynchronization therapy: The Task Force for Cardiac Pacing and Cardiac Resynchronization Therapy of the European Society of Cardiology. Developed in collaboration with the European Heart Rhythm Association. Eur Heart J. 2007;28:2256-95. https://doi.org/10.1093/eurheartj/ehm305

13. Littmann L, Symanski JD. Hemodynamic implications of left bundle branch block. J Electrocardiol. 2000;33:115-21. https://doi.org/10.1054/jelc.2000.20330

14. Saxon LA, Kerwin WF, Cahalan MK, Kalman JM, Olgin JE, Foster E, et al. Acute effects of intraoperative multisite ventricular pacing on left ventricular function and activation/contraction sequence in patients with depressed ventricular function. J Cardiovasc Electrophysiol. 1998;9:13-21. https://doi.org/10.1111/j.1540-

8167.1998.tb00862.x

15. Kerwin WF, Botvinick EH, O’Connell JW, Merrick SH, DeMarco T, Chatterjee K, et al. Ventricular contraction abnormalities in dilated cardiomyopathy: effect of biventricular pacing to correct interventricular dyssynchrony. J Am Coll Cardiol. 2000;35:1221-7. https://doi.org/10.1016/s0735-1097(00)00555-6

16. Birnkrant DJ, Bushby K, Bann CM, Apkon SD, Blackwell A, Brumbaugh D, et al. Diagnosis and management of Duchenne muscular dystrophy, part 1: diagnosis, and neuromuscular, rehabilitation, endocrine, and gastrointestinal and nutritional management. Lancet Neurol. 2018;17:251-67. https://doi.org/10.1016/s1474-4422(18)30024-3

17. Lopez L, Colan SD, Frommelt PC, Ensing GJ, Kendall K, Younoszai AK, et al. Recommendations for quantification methods during the performance of a pediatric echocardiogram: a report from the Pediatric Measurements Writing Group of the American Society of Echocardiography Pediatric and Congenital Heart Disease Council. J Am Soc Echocardiogr Off Publ Am Soc Echocardiogr. 2010;23:465-95; quiz 576-7.

https://doi.org/10.1016/j.echo.2010.03.019

18. Voigt J-U, Pedrizzetti G, Lysyansky P, Marwick TH, Houle H, Baumann R, et al. Definitions for a common standard for 2D speckle tracking echocardiography: consensus document of the EACVI/ASE/Industry Task Force to standardize deformation imaging. J Am Soc Echocardiogr Off Publ Am Soc Echocardiogr. 2015;28:183-93. https://doi.org/10.1093/ehjci/jeu184

19. Chubb H, Ceresnak SR, Motonaga KS, Dubin AM. A proposed method for the calculation of age-dependent QRS duration z-scores. J Electrocardiol. 2020;58:132-4. https://doi.org/10.1016/j.jelectrocard.2019.12.004

20. Surawicz Borys, Childers Rory, Deal Barbara J., Gettes Leonard S. AHA/ACCF/HRS Recommendations for the Standardization and Interpretation of the Electrocardiogram. Circulation. American Heart Association; 2009;119:e235-40. https://doi.org/10.1016/j.jacc.2008.12.013

21. Thomas TO, Jefferies JL, Lorts A, Anderson JB, Gao Z, Benson DW, et al. Autonomic Dysfunction: A Driving Force for Myocardial Fibrosis in Young Duchenne Muscular Dystrophy Patients? Pediatr Cardiol. 2015;36:561-8. https://doi.org/10.1007/s00246-014-1050-z 
22. Thomas VC, Cumbermack KM, Lamphier CK, Phillips CR, Fyfe DA, Fornwalt BK. Measures of dyssynchrony in the left ventricle of healthy children and young patients with dilated cardiomyopathy. J Am Soc Echocardiogr Off Publ Am Soc Echocardiogr. 2013;26:142-53. https://dx.doi.org/10.1016\%2Fj.echo.2012.10.014

23. Tanaka H, Nesser H-J, Buck T, Oyenuga O, Jánosi RA, Winter S, et al. Dyssynchrony by speckle-tracking echocardiography and response to cardiac resynchronization therapy: results of the Speckle Tracking and Resynchronization (STAR) study. Eur Heart J. 2010;31:1690-700. https://doi.org/10.1093/eurheartj/ehq213

24. Risum N, Jons C, Olsen NT, Fritz-Hansen T, Bruun NE, Hojgaard MV, et al. Simple regional strain pattern analysis to predict response to cardiac resynchronization therapy: rationale, initial results, and advantages. Am Heart J. 2012;163:697-704. https://doi.org/10.1016/j.ahj.2012.01.025

25. Yu C-M, Chau E, Sanderson JE, Fan K, Tang M-O, Fung W-H, et al. Tissue Doppler echocardiographic evidence of reverse remodeling and improved synchronicity by simultaneously delaying regional contraction after biventricular pacing therapy in heart failure. Circulation. 2002;105:438-45. https://doi.org/10.1161/hc0402.102623

26. Bharucha T, Khan R, Mertens L, Friedberg MK. Right Ventricular Mechanical Dyssynchrony and Asymmetric Contraction in Hypoplastic Heart Syndrome are Associated with Tricuspid Regurgitation. J Am Soc Echocardiogr. 2013;26:1214-20. https://doi.org/10.1016/j.echo.2013.06.015

27. Zhang X, Ha S, Wang X, Shi Y, Duan S, Li Z. Speckle tracking echocardiography: clinical applications in cardiac resynchronization therapy. Int J Clin Exp Med. 2015;8:6668-76.

28. Suffoletto MS, Dohi K, Cannesson M, Saba S, Gorcsan J. Novel speckle-tracking radial strain from routine black-andwhite echocardiographic images to quantify dyssynchrony and predict response to cardiac resynchronization therapy. Circulation. 2006;113:960-8. https://doi.org/10.1161/circulationaha.105.571455

29. Gorcsan J, Oyenuga O, Habib PJ, Tanaka H, Adelstein EC, Hara H, et al. The Relationship of Echocardiographic Dyssynchrony to Long-Term Survival Following Cardiac Resynchronization Therapy. Circulation. 2010;122:1910-8. https://dx.doi.org/10.1161\%2FCIRCULATIONAHA.110.954768

30. Gorcsan J, Tanabe M, Bleeker GB, Suffoletto MS, Thomas NC, Saba S, et al. Combined longitudinal and radial dyssynchrony predicts ventricular response after resynchronization therapy. J Am Coll Cardiol. 2007;50:1476-83. https://doi.org/10.1016/j.jacc.2007.06.043

31. Shrout PE, Fleiss JL. Intraclass correlations: uses in assessing rater reliability. Psychol Bull. 1979;86:420-8.

32. Koo TK, Li MY. A Guideline of Selecting and Reporting Intraclass Correlation Coefficients for Reliability Research. J Chiropr Med. 2016;15:155-63. https://dx.doi.org/10.1016\%2Fj.jcm.2016.02.012

33. Hor KN, Wansapura JP, Al-Khalidi HR, Gottliebson WM, Taylor MD, Czosek RJ, et al. Presence of mechanical dyssynchrony in Duchenne muscular dystrophy. J Cardiovasc Magn Reson Off J Soc Cardiovasc Magn Reson. 2011;13:12. https://doi.org/10.1186/1532-429X-13-12

34. Bilchick KC, Salerno M, Plitt D, Dori Y, Crawford TO, Drachman D, et al. Prevalence and distribution of regional scar in dysfunctional myocardial segments in Duchenne muscular dystrophy. J Cardiovasc Magn Reson Off J Soc Cardiovasc Magn Reson. 2011;13:20. https://dx.doi.org/10.1186\%2F1532-429X-13-20

35. Frankel KA, Rosser RJ. The pathology of the heart in progressive muscular dystrophy: epimyocardial fibrosis. Hum Pathol. 1976;7:375-86. https://doi.org/10.1016/s0046-8177(76)80053-6

36. Yasuda S, Townsend D, Michele DE, Favre EG, Day SM, Metzger JM. Dystrophic heart failure blocked by membrane sealant poloxamer. Nature. 2005;436:1025-9. https://doi.org/10.1038/nature03844

37. Bilchick KC, Saha SK, Mikolajczyk E, Cope L, Ferguson WJ, Yu W, et al. Differential regional gene expression from cardiac dyssynchrony induced by chronic right ventricular free wall pacing in the mouse. Physiol Genomics. 2006;26:109-15. https://doi.org/10.1152/physiolgenomics.00281.2005 
38. Wilke L, Abellan Schneyder FE, Roskopf M, Jenke AC, Heusch A, Hensel KO. Speckle tracking stress echocardiography in children: interobserver and intraobserver reproducibility and the impact of echocardiographic image quality. Sci Rep. Nature Publishing Group; 2018;8:1-12. https://doi.org/10.1038/s41598-018-27412-2

39. Bleeker GB, Yu C-M, Nihoyannopoulos P, de Sutter J, Van de Veire N, Holman ER, et al. Optimal use of echocardiography in cardiac resynchronisation therapy. Heart Br Card Soc. 2007;93:1339-50. https://dx.doi.org/10.1136\%2Fhrt.2005.076422

40. Anderson LJ, Miyazaki C, Sutherland GR, Oh JK. Patient selection and echocardiographic assessment of dyssynchrony in cardiac resynchronization therapy. Circulation. 2008;117:2009-23. https://doi.org/10.1161/circulationaha.107.721332

41. Urheim Stig, Edvardsen Thor, Torp Hans, Angelsen Bjørn, Smiseth Otto A. Myocardial Strain by Doppler Echocardiography. Circulation. 2000;102:1158-64. https://doi.org/10.1161/01.cir.102.10.1158

42. Edvardsen T, Skulstad H, Aakhus S, Urheim S, Ihlen H. Regional myocardial systolic function during acute myocardial ischemia assessed by strain Doppler echocardiography. J Am Coll Cardiol. 2001;37:726-30. https://doi.org/10.1016/s0735-1097(00)01160-8

43. McNally EM, Kaltman JR, Benson DW, Canter CE, Cripe LH, Duan D, et al. Contemporary cardiac issues in Duchenne muscular dystrophy. Working Group of the National Heart, Lung, and Blood Institute in collaboration with Parent Project Muscular Dystrophy. Circulation. 2015;131:1590-8. https://doi.org/10.1161/circulationaha.114.015151

44. Spurney C, Shimizu R, Morgenroth LP, Kolski H, Gordish-Dressman H, Clemens PR, et al. Cooperative International Neuromuscular Research Group Duchenne Natural History Study demonstrates insufficient diagnosis and treatment of cardiomyopathy in Duchenne muscular dystrophy. Muscle Nerve. 2014;50:250-6.

https://doi.org/10.1002/mus.24163

45. Viollet L, Thrush PT, Flanigan KM, Mendell JR, Allen HD. Effects of angiotensin-converting enzyme inhibitors and/or beta blockers on the cardiomyopathy in Duchenne muscular dystrophy. Am J Cardiol. 2012;110:98-102. https://doi.org/10.1016/j.amjcard.2012.02.064

46. Ogata H, Ishikawa Y, Ishikawa Y, Minami R. Beneficial effects of beta-blockers and angiotensin-converting enzyme inhibitors in Duchenne muscular dystrophy. J Cardiol. 2009;53:72-8. https://doi.org/10.1016/j.jjcc.2008.08.013

47. Matthews E, Brassington R, Kuntzer T, Jichi F, Manzur AY. Corticosteroids for the treatment of Duchenne muscular dystrophy. Cochrane Database Syst Rev. 2016;CD003725. https://doi.org/10.1002/14651858.cd003725.pub4

48. Bleeker GB, Holman ER, Steendijk P, Boersma E, van der Wall EE, Schalij MJ, et al. Cardiac resynchronization therapy in patients with a narrow QRS complex. J Am Coll Cardiol. 2006;48:2243-50.

https://doi.org/10.1016/j.jacc.2006.07.067

49. Yu C-M, Chan Y-S, Zhang Q, Yip GWK, Chan C-K, Kum LCC, et al. Benefits of cardiac resynchronization therapy for heart failure patients with narrow QRS complexes and coexisting systolic asynchrony by echocardiography. J Am Coll Cardiol. 2006;48:2251-7. https://doi.org/10.1016/j.jacc.2006.07.054

50. Bleeker Gabe B., Kaandorp Theodorus A.M., Lamb Hildo J., Boersma Eric, Steendijk Paul, de Roos Albert, et al. Effect of Posterolateral Scar Tissue on Clinical and Echocardiographic Improvement After Cardiac Resynchronization Therapy. Circulation. American Heart Association; 2006;113:969-76.

https://doi.org/10.1161/circulationaha.105.543678

\section{Figures}




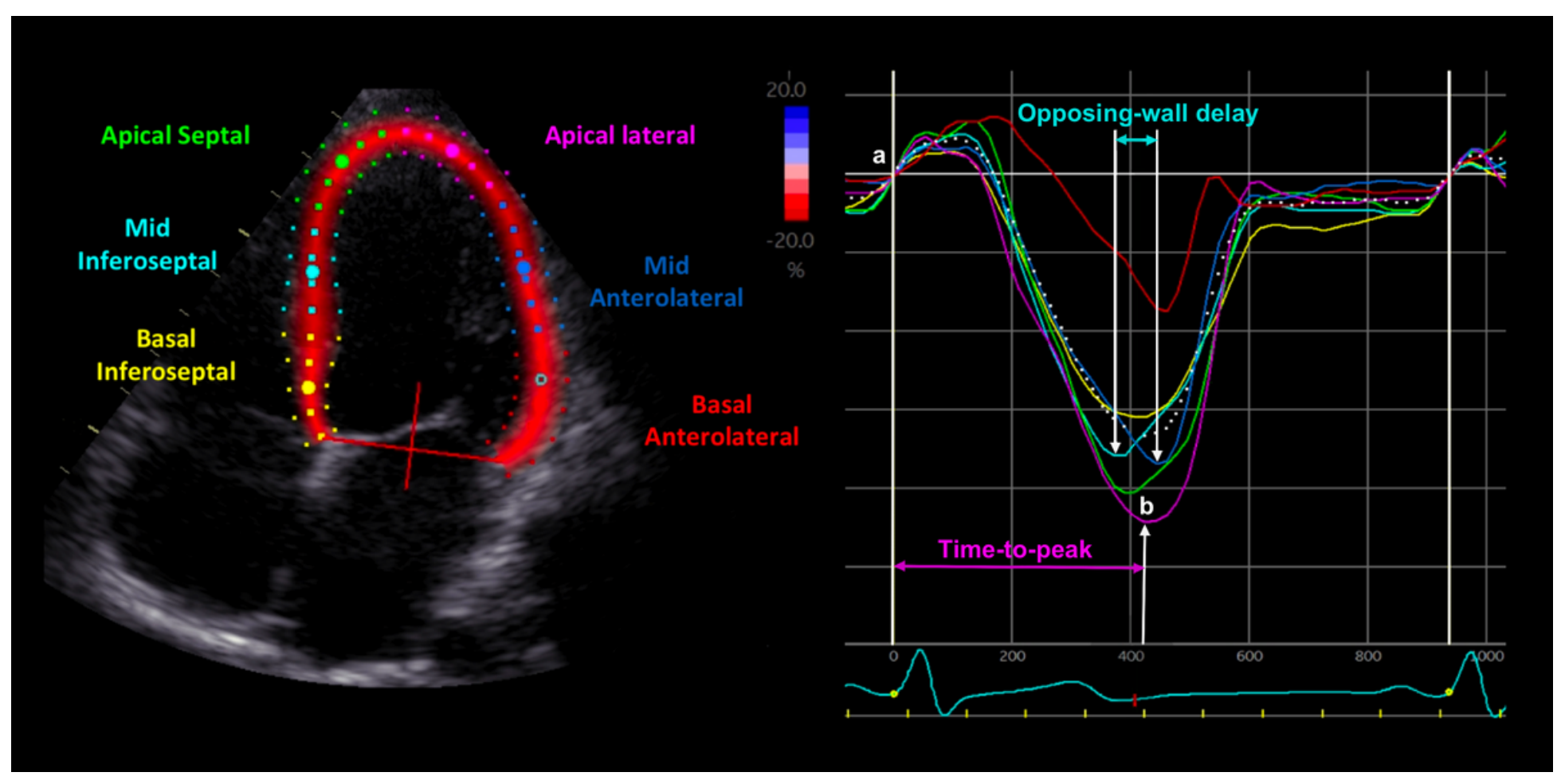

\section{Figure 1}

LV longitudinal mechanical dyssynchrony analysis using 2D-STE Legend: On the left side, the LV apical 4-chamber view is automatically divided into 6 segments. On the right side, six color curves represent the 2D-strain deformation corresponding to those segments during a cardiac cycle (simultaneous electrocardiogram is seen at the bottom): yellow (basal inferoseptal segment), light blue (mid inferoseptal segment), green (apical septal segment), purple (apical lateral segment), dark blue (mid anterolateral segment), and red (basal anterolateral segment). Here, the time-to-peak delay of the apical lateral segment (purple curve) is measured between the beginning of the QRS interval (a) and the systolic strain peak (b); and the opposing-wall delay between the two mid segments is measured between the systolic strain peak of the mid inferoseptal segment (light blue curve) and the systolic strain peak of the mid anterolateral segment (dark blue curve). 


\section{Mean corrected time-to-peak delays}

\section{Children with DMD}

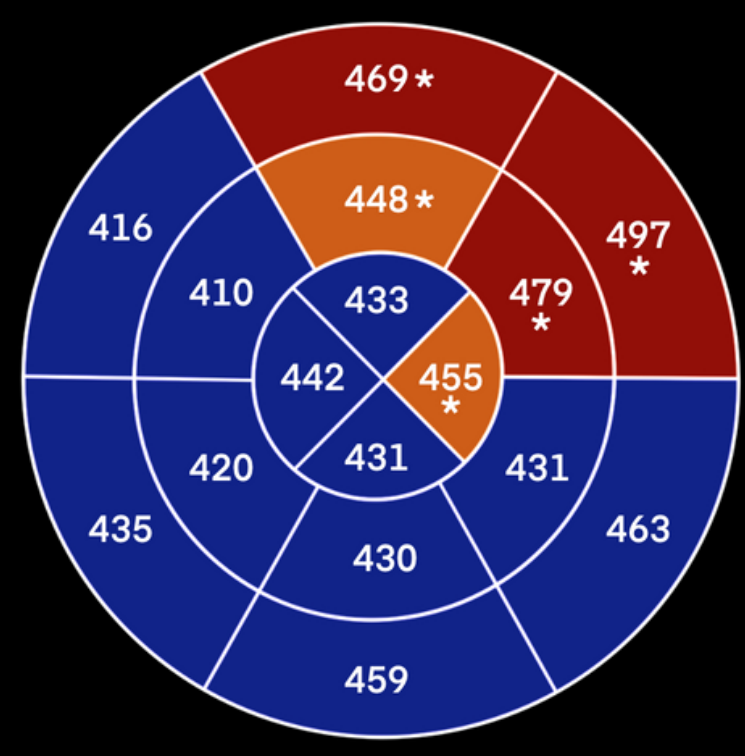

\section{Healthy matched controls}

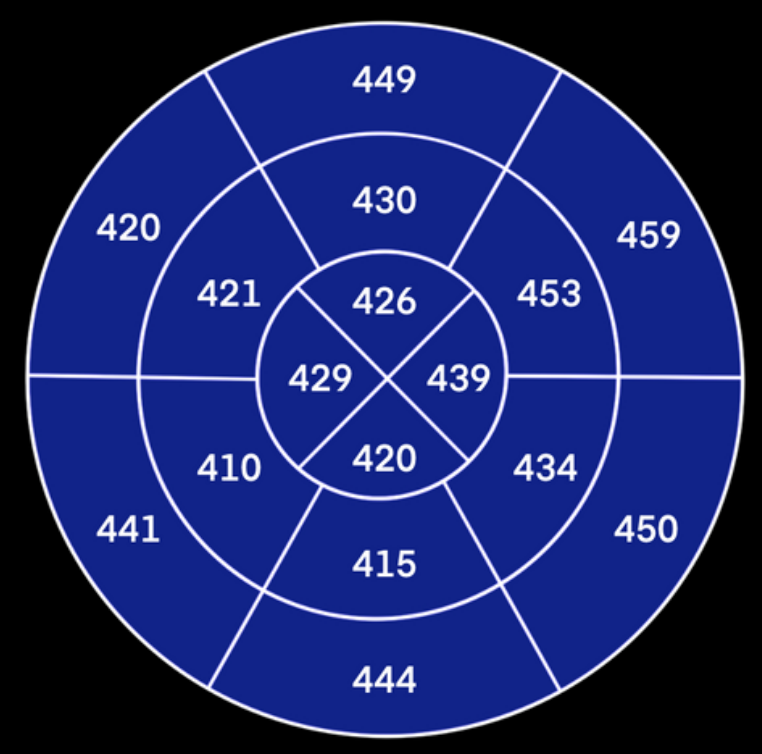

Difference in time-to-peak delays

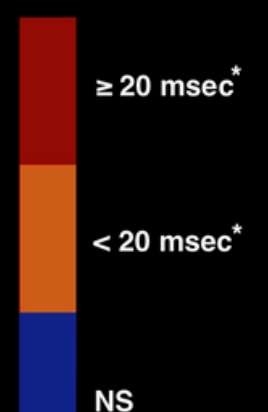

Values are expressed in msec

* Significant P-values (comparaison between DMD and control groups)

Figure 2

Comparison of LV longitudinal time-to-peak delays between DMD and control groups Legend: The two figures represent, for each group, the time-to-peak delay of each LV segment, corrected by heart rate (using Bazett's formula, expressed in msec), using the 16-segment bull's eye model of myocardial segmentation. The boxes in red represent the segments for which time-to-peak delays were significantly different $(\mathrm{P}<0.05)$ between the two groups with a magnitude of the difference $\geq 20 \mathrm{msec}$ (basal anterolateral, mid anterolateral, and basal anterior segments). The boxes in orange represent the segments for which time-to-peak delays were significantly different $(\mathrm{P}<0.05)$ between the two groups with a magnitude of the difference $<20 \mathrm{msec}$ (mid anterior and apical lateral segments). The boxes in blue represent the segments for which time-to-peak delays were not significantly different between the two groups (NS, non-significant).

\section{Supplementary Files}

This is a list of supplementary files associated with this preprint. Click to download.

- SupplementaryTables1.doc

- SupplementaryTables2.doc 